\title{
Analysis and Research on the E-business Model of Mtime
}

\author{
Wenrong Jiang \\ School of Computer and Information, Shanghai Polytechnic University, Shanghai, China
}

\begin{abstract}
Through analyzing Mtime's marketing model to know about Mtime, by comparing with Douban, Ying Huochong and other websites to find out Mtime's pros and cons. Analyze Mtime to understand what the core capacity it has, what points attract users to browse, what's the audience crowd and what needs to be improved in terms of scope and so on.
\end{abstract}

Keywords-mtime; business model; profit model; core competence; management model; technology model; capital model

\section{INTRODUCTION}

Mtime relies on its huge database and user-generated content such as comments on films, joining with many pictures, theaters and some major movie channels, to integrate any places' news and information to form a website with its own features, and provides most movie lovers an excellent communicating platform.

In Mtime' s profit source figure, not only the pictures, cinemas, some major movie channels but also search engines, website users, the third payment platform and so on.

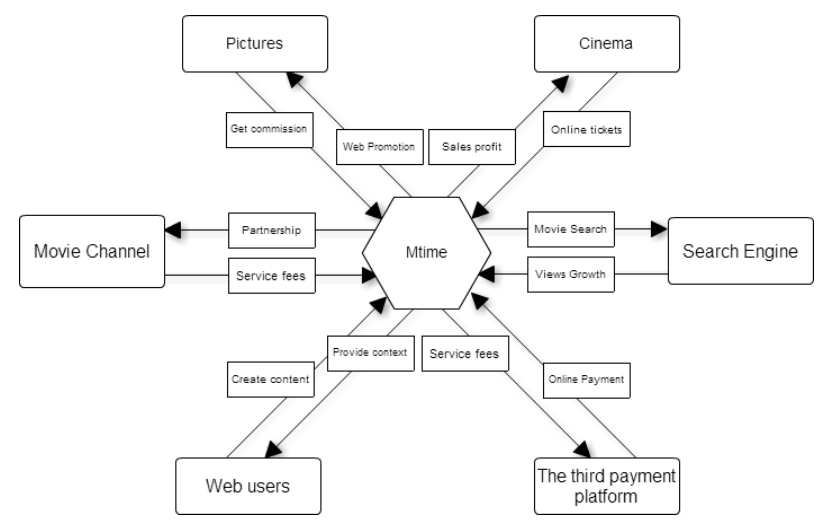

FIGURE I. PROFIT SOURCE

\section{MTIME Business ModEL}

\section{A. Strategic Objectives}

Mtime's strategic goal is to make movie lovers and people who want to find a good movie watch their own satisfying movies. After long efforts to establish their own professional Movie Database, which includes millions of movies' information, and at the developing of the website, it also updates the website's news such as the latest movies and information worldwide.

\section{B. Target Users}

Mtime orientates in movie lovers and employment about movie or television, with higher standards, more professional comments, and owns commercial color. Major users are movie lovers and basically have a higher level of appreciation and requirements about movies, these people own both higher and spiritual quest, also have a more profound knowledge and understanding about movies, and they should have some spare time to write comments on film carefully.

\section{Products and Services}

\section{1) Movie Information}

Since Mtime cooperates with many domestic and foreign pictures, so it can attract a lot of fans love the fresh news because of the first-hand and exclusive movie information.

\section{2) Movie Database}

Mtime relies on its own rich movie resources to provide users with millions of movies, movie theaters and the number of information queries. Users can through classify, release time, and the audience rating scale to query movie information or other useful news.

\section{3) User Forum}

Mtime through their own unique user orientation has a lot of loyal users, all registered users have their personal services space and Mtime still provides users a function to make their own interest group to know about others who have the same hobbies. The function named my time, that every registered members can open its own blog homepage, also known as the personal movie forum, which includes friends, logs, photo albums, groups, games, polls, critics, and other Mtime Toolbox.

\section{Profit Model}

\section{1) New movie online promotion}

Since Mtime cooperate with a number of domestic and foreign pictures, and through long-term' s accumulation of popularity and high orientation, it can promote a new movie online to get some profit.

\section{2) Paid to provide website content}

Mtime can have an agreement with Google, Baidu to provide film-related information search services for search engines. 


\section{3) Internet and phone ticket}

Mtime cooperates with various cinemas all over the country to launch Mtime features: movie passes. Users can submit orders directly on Mtime, use Paypal or other payment platform online to purchase movie passes, and can be converted into any theaters' tickets cooperated within the validity period.

\section{4) Cinema online promotion}

Mtime cooperates with a number of cinemas in dozens of cities of the country, by introducing cinema information on website such as its address, environment, scale, services and promotions, etc., and let users to check the latest movie showtimes, movie theaters to obtain a kind of promotional fees.

\section{E. Core Competencies}

\section{1) Authoritative, rich, latest and accurate information about movies.}

Mtime owns a huge number of professional movie editors and communication staff, they are able to update the latest movie information for the site in the time, and the vast majority of this information are copyrighted Mtime exclusive feature or property. This is which the same movie sites can not be compared with.

\section{2) Largest movie database}

Mtime owns the largest movie and TV information databases, including over 85,000 movies all over about 154 countries, more than 51 countries or areas' 7600 TV series, more than 720 filmmakers and many pictures.

\section{3) More mature marketing operation}

With strong financial assistance, Mtime aims to develop a set of comprehensive targeted marketing operation system, to provide a reference solution for pictures, theaters, major movie channels website.

\section{4) High popularity of user views}

As the target population positioning accurated, the powerful website features, the current site has gathered more than a million people registered user, but the user experience now than before Mtime's not good, because the site more than a few commercials, these commercial components and message lead to the loss of a large part of Mtime loyal users, there is no shortage of the arrival of newcomers.

\section{MTIME Business MODEL}

Mtime's philosophy is "from online to offline, online driven by offline." For a huge database of a movie site, this concept is extremely accurate, by strong online promotion, promote the rapid growth of the line at the box office, to achieve a win-win model. Since Mtime's authoritative information, professional critics, as well as the effect of a significant promotion in the country, it attracts a large number of film companies to join with, but also on the other hand starts its own brand.
Mtime's business strategy, according to "website developing in three stages," step by step.

First stage: Shaping website brand. Mtime done less publicity and promotion in the first time, the main energy used to do the following things:

(1) Establish a resource-rich enough Movie Database;

(2) To attract a large number of high-end film-related people;

(3) Shaping the quality of their own brand.

Second stage: become well-known site. At this stage, except to improve the first stage, to promote and take corresponding measures on earnings. Mtime site's videos, games, groups, and other small features are constantly improving. In cinema this category, Mtime cooperates with national theaters, bring both profits and their improved quality.

The third stage: Website competition. Currently Mtime is developing at this stage, on the one hand, the site has gradually entered the promotion of professional standards, constantly sum up successful models and continue to strengthen; on the other hand, according to the website' s new markets, developing new products or new features to instant targeted and flexible marketing strategies.

Now, Mtime has launched movie advertising, wireless pay TV services, movie tickets and DVD sales, as well as a series of film-related e-commerce. Through these services Mtime will get more profit point, to further expand the scale and influence of the site.

\section{Mtime Technology Model}

Mtime's technical pattern positions on the system's stability and security aspects. Currently the database schema Mtime used for SQL Server Cluster, and the use of technology to achieve high efficiency clustered index is called. Because the core of Mtime service is powerful movie database, so there are high demands on database indexing technology, the clustered index technology can achieve this requirement better.

On the other hand, Mtime as a film community, interactive technology and user interface for interactive features should also have a higher standard. Mtime's background programming language used. NET development, some features using $\mathrm{C}$ \# development, front desk functions and services used mainly AJAX, XML, XSLT technology development, to achieve website's interactive features through ADO and JavaScript.

\section{Mtime Management ModeL}

Unlike the rest of the domestic movie site, Mtime's outstanding advantage is that, Beijing Network Technology Co., abundant financial aid it, in addition it also has a large number of professional movie editors and critics, which makes the whole site from the scale to richness of content, professional standards in all aspects and the overall operating strategy, marketing tools, and copyright protection at the forefront of similar movie sites.

For the professional quality and site content, Mtime is more stringent in quality management. Mtime encourages 
users to upload their own copyright, high-quality movie pictures, posters, stills, but also allows the user to take the initiative to provide information on the film, but it will be reviewed by a professional website editor. Mtime's high level of specialization, was known as China's IMDB, and get the famous pictures' favor to reach a cooperation agreement and join with expand their business.

\section{Mtime CAPITAL Model}

Mtime has won global venture capital fund DFJ's an investment, specific investment amount is unknown, the Managing Partner of DFJ, Zhang $\mathrm{Xi}$ is the leading participants in the investment Mtime's chairman.
The Mtime's partner Beijing Network Technology Co., Ltd. DanceArt time also offers a higher financial assistance, and laid a solid economic foundation for long-term development of Mtime.

Mtime rarely disclosed the information on its operations and the company, therefore, Beijing Network Technology Co., Ltd. DanceArt time, has profit or not still wasn't known. But what is certain is that, Mtime need more capital to expand their business, such as public financing is only a matter of time. From the current development situation of view, Mtime still needs to find more profitable point to expand the influence and scale, while for the sake of users, the site should also be a lot of focus on the user experience, reduce website commercialized atmosphere.

TABLE I. MTIME COMPARES WITH OTHER SIMILAR MOVIE SITES

\begin{tabular}{|c|c|c|c|}
\hline Comparison & Mtime & Dou Ban & Ying Huochong \\
\hline Provide content & $\begin{array}{l}\text { Entertainment information, filmmakers } \\
\text { festival information, film reviews }\end{array}$ & Television, books, music reviews & $\begin{array}{l}\text { Film reviews, filmmakers festival } \\
\text { information, video sharing, theme } \\
\text { packaging }\end{array}$ \\
\hline Content resource & ugc and mild editing & ugc & Original editing and ugc \\
\hline Service & Blog, movie, database, bbs & Sns, Blog aggregation, bbs & $\begin{array}{l}\text { sns, upload videos, guides TV, } \\
\text { interactive entertainment, bbs }\end{array}$ \\
\hline Features section & Blog, allmov movie resource & Nine-Clock & Theme, Amoy movies, Asian rankings \\
\hline Founded date & 1999 & 2004 & 2007 \\
\hline Users loyalty & Normal & $\begin{array}{l}\text { High, Because complete ugc } \\
\text { content }\end{array}$ & Low \\
\hline Operating cost & High & High & Low \\
\hline Business Model & $\begin{array}{l}\text { Advertising and offline activities, online } \\
\text { ticket }\end{array}$ & $\begin{array}{l}\text { Produce shopping guide mode by } \\
\text { users' information and so on }\end{array}$ & $\begin{array}{l}\text { Theme pack promotion, product } \\
\text { placement }\end{array}$ \\
\hline Target users & $\begin{array}{l}\text { Film and television practitioners and } \\
\text { high-end fans }\end{array}$ & Volkswagen movie lovers & High-end fans and practitioners \\
\hline Promotion & Promotion activities, web promotion & Word of mouth marketing & No formal promotion \\
\hline Ascendancy & $\begin{array}{c}\text { More mature market operation, optimized } \\
\text { operating system }\end{array}$ & $\begin{array}{c}\text { Large user base and appropriate } \\
\text { market opportunities }\end{array}$ & Original content \\
\hline Future prospects & $\begin{array}{l}\text { Strong financial background, more } \\
\text { market-oriented development }\end{array}$ & $\begin{array}{l}\text { Scale users, can be derived } \\
\text { relatively diverse earnings point }\end{array}$ & $\begin{array}{l}\text { Unknown, similar to the movie } \\
\text { magazines, guides can provide } \\
\text { multifaceted cooperation }\end{array}$ \\
\hline
\end{tabular}

\section{SUGGESTIONS}

After such a long time development, Mtime has became a leading vertical portal pictures, was friends known as "China's IMDB". Although similar in some respects with Dou Ban, but Mtime' s content and services are more vertical, professional editors provide films information and television shows, higher professional level than the rest of similar websites. In addition, its operation teams have a professional search engine optimization personnel in the search engine ranking and more movies nouns occupy a favorable advantage, and thus a high ranking search rankings, SEO also contributes a lot cumulative.

But the only drawback is, Mtime positions for high-end crowd who do not provide movie download site or on-demand service, which is obviously virtually lost a lot of ordinary users. Although Mtime's original intention was to protect the copyright of movies information, but relying solely on movie trailers are still unable to meet the needs of domestic users, this does not meet the status of the domestic industry. Mtime should proceed from one hand to promote genuine movie considered reasonable and lawful manner webcast or on-demand services.
In terms of the movie rating system, Mtime should also be timely film scoring mechanism, through technical means and human intervention to curb the further expansion of such imbalances trends, promote fairness, justice, health, cultural sites, so as to become a veritable "China the IMDB ".

\section{ACKNOWLEDGEMENT}

This work is supported by the Key Disciplines of Computer Science and Technology of Shanghai Polytechnic University under Grant No. XXKZD1604.

\section{REFERENCES}

[1] Wenrong Jiang, Jian Chen. Traditional Enterprises Transformation and Strategy to Deal with E-Commerce[J]. 2015 4th International Conference on Physical Education and Society Management (ICPESM 2015), Singapore, December 6-7, 2015, Lecture Notes in Management Science, 2015(12), Vol 47, 301-306. IDS: BF3BX

[2] Wenrong Jiang. Analysis the O2O marketing model about old network website[J]. The Second International Conference on Economic and Business Management (FEBM2017), Shanghai, China, ATLANTIS Press. October 21-23, 2017, 507-512.

[3] Wenrong Jiang. The Analysis of SEO from Jumei Youpin's Crash[J]. The 2017 International Conference on Applied Mechanics and Mechanical Automation(AMMA2017), HongKong, China, DEStech Publications, Inc. June 23, 2017, 401-405. 
[4] Wenrong Jiang. Analysis of B2B E-commerce Development With a Case Study of Made-in-China Website[J]. 4th International Conference on Business, Education, Law and Interdisciplinary Studies(BELIS 2017), London, UK, June 29, 2017, 130-135.

[5] Wenrong Jiang, Yingyan Liu. Analysis of the double 11 ouyeel business promotion effectiveness[C]. 2016 ISSGBM International Conference on Information, Communication and Social Sciences (ISSGBM-ICS 2016), Dubai, United Arab Emirates, Singapore Management and Sports Science Institute, October 8, 2016, 49-55. WOS: 000391774900010

[6] Wenrong Jiang. Analysis of the E-commerce websiteLianliangou[C]. 2016 2nd International Conference on Electronics, Network and Computer Engineering (ICENCE2016), Yinchuan, China, Advances in Computer Science Research, Vol67. Auguest $13,2016,674-679$.

[7] Wenrong Jiang, Shiwei Li. Analysis of Xiaomi Tech's E-commerce model[J]. 2nd International conference on E-commerce and Contemporary Economic Development (ECED 2015), Nanjing, China, December 5-6, 2015, DEStech Publications, Inc. 196-200. WOS: 000380277700040

[8] Wenrong Jiang, Jian Chen.Analysis of the wabsite-Hj operations[J] 2015 3nd International Conference on Applied Social Science Research (ICASSR 2015), Limassol, Cyprus, October 4-5, 2015, 103-106. WOS: 000386102200029 